\title{
A case report of hypo-parathyroidism with psychiatric complications
}

\author{
S. S. Palia, J. Dawkins and D. Webb
}

Hyper and hypo-parathyroidism both lead to psychiatric disorder. In the former the hypercalcaemia is responsible for an acute or chronic organic reaction, depending on the speed with which the calcium has risen. The hypocalcaemia of the latter is more likely to present as tetany, and enters into the differential diagnosis of hysterical over-breathing (Hill et al, 1987). Hypo-parathyroidism most commonly follows inadvertent parathyroidectomy during thyroidectomy when an abrupt fall in serum calcium can precipitate psychiatric disturbance. The mental state is closely related to the serum calcium level. If this is borderline there may only be symptoms such as anxiety, depression and tension, but with lower levels acute confusion may result. More chronic symptoms occur in long standing hypo-parathyroidism, such as poor concentration, emotional lability and impaired intelligence (Kendall \& Zealley, 1983).

This unusual condition of hypo-parathyroidism may arise from a variety of causes, but the clinical feature in common is tetany. Biochemically a depressed plasma calcium and a raised plasma phosphate are characteristic. This condition can be due to post-operative hypo-parathyroidism, infantile hypo-parathyroidism, idiopathic hypoparathyroidism which may develop at any age, and exceptionally in association with hypomagnesaemia. Pseudo-hypo-parathyroidism in which there is tissue resistance to the effects of parathyroid hormone needs to be distinguished. Pseudo-hypo-parathyroidism presents with the biochemical features of hypo-parathyroidism and also aberrant calcification, cataracts, mental retardation and skeletal abnormality, the latter include small stocky stature and short fourth and fifth metacarpals.

Denko \& Kaelbling (1962) reviewed the literature on hypo-parathyroidism and concluded that at least half the cases attributable to surgery had psychiatric symptoms usually in the form of acute organic psychiatric syndromes. In idiopathic cases of hypo-parathyroidism, chronic psychiatric syndromes are more common. Less frequent complications are depression, irritability and nervousness (pseudo-neurosis). Manic de- pressive and schizophrenic disorders are rare (Lisham, 1978) and may be coincidental. Hypoparathyroidism is associated with organic brain syndromes such as confusion, delirium etc., psychosis and depression (Leigh \& Kramer, 1984). The organic brain syndrome is reversed in approximately half of patients who have appropriate treatment.

We report a case of a 30-year-old mother of four young children who presented with recurrent acute psychiatric disturbance, and for nearly 18 months the diagnosis of hypo-parathyroidism was either not suspected or missed.

\section{Case report}

Miss TC, 30 years of age, was referred to us (October 94) by her social worker who was becoming increasingly worried about her behaviour. She was becoming confused and paranoid that people were creeping up behind her. She had started wandering and was frequently found sleeping in doorways and even a local graveyard. She had some depresstve symptoms and feelings of intense guilt at not being able to look after her four children who were all in foster care. She was a regular abuser of intravenous amphetamine and had been charged with shoplifting and credit card fraud, for which she was awaiting court appearances. The previous year, February 1993. she had been admitted to a nearby psychiatric hospital after slashing her wrists because her auditory hallucinations had told her to do so. The diagnosis on this occasion was "personality disorder". Her blood tests on this admission were all normal. A serum calcium check was not done. She had not menstruated for some time and they noted that she was underweight ( $34.3 \mathrm{kgs})$.

She was admitted under the physicians at our hospital 2 months prior to this admission having taken an overdose of paracetamol tablets. It was interesting to note that she had two liver function tests before her discharge as being "medically fit" - both tests showed her serum calcium to be abnormally low at $1.71 \mathrm{mmol} / 1$ 
and $2.00 \mathrm{mmol} / 1$ respectively (the normal range being $2.10-2.60 \mathrm{mmol} / 1)$. No comment was made about her unusually short stature $(135 \mathrm{~cm})$. She had no other past medical history except for Caesarean sections for each of her 4 children presumably for cephalopelvic disproportion.

She had no family psychiatric history. Her biological mother left when she was aged 2 and was also short of stature. Her biological father died when the patient was aged 10, the cause of death was not known. She was brought up by her mother's friend. She had three brothers who were all of normal height. In her personal history, she left school with no qualifications and has never worked. She had her first child aged 18.

On admission she was taking paroxetine $20 \mathrm{mg}$ o.d. prescribed by her GP. Mental state examination showed a very small thin woman weighing $38 \mathrm{kgs}$ and $135 \mathrm{~cm}$ in height, inappropriately giggling throughout initial interview, and having morbid thoughts about graveyards but also feelings of guilt about not being able to look after her children. She also had intense paranoid feelings that somebody was watching her and sometimes she heard her name being called. She was fully orientated in time, place and person. She appeared of low normal intelligence but was able to read and write. She had a poor memory for recent events and had difficulty sustaining concentration. Physical examination apart from her small stature and 'elf-like' appearance was unremarkable. There were signs of intravenous drug abuse on her right arm.

Impression at this stage was of possible psychotic illness, maybe drug induced but endocrinological abnormality was questioned in view of her striking appearance. Stelazine $5 \mathrm{mg}$ t.d.s. was administered and the paranoid psychotic features became less evident. She nevertheless remained absent-minded and rather vacant. She displayed fluctuating confusional state with agitation, apathy, paranoia and auditory hallucination.

Investigations comprising B12/folate, full blood count, Venereal Disease Research Laboratory/ treponemal haemagglutination test, hepatitis screen, urine screen for drugs, urea and electrolytes, thyroid function test and EEG were normal. Liver function tests were abnormal as follows:

(a) serum aspartate transaminase 87 IU/1 (normal range 0-40);

(b) alkaline phosphatase 144 IU/1 (normal range 30-120);

(c) gamma GT $58 \mathrm{IU} / 1$ (normal range 0-50);

(d) calcium $1.89 \mathrm{mmol} / 1$ (normal range 2.10-2.60);

(e) phosphate 1.60 (normal range 0.80-1.50).

Serum calcium was measured on several occasions following this and remained lower than normal range. The patient had no physical symptoms of hypocalcaemia. Primary hypo-parathyroidism was confirmed by serum para-thormone being less than $0.8 \mathrm{pmol} / 1$ - normal range being $(0.9-5.4) \mathrm{pmol} / \mathrm{l}$. Alfacalcidol is a shortacting and potent vitamin $D$ analogue and is known to be effective in treating hypocalcaemia in hypo-parathyroidism, chronic renal failures and malabsorption. This drug was commenced at $500 \mathrm{ng}$ daily with good response.

With reassurance and a small amount of trifluoperazine $10-15 \mathrm{mg}$ daily, most of her disturbed behaviour settled, although she continued to display inappropriate giggles and shallow emotions, moods and rapport. She did not experience any craving for drug abuse. She was successfully discharged to hostel accommodation under supervision from the local Community Mental Health Team.

\section{Discussion}

From a psychiatric point of view the initial working diagnosis was of drug induced psychotic state, but her psychosis took some time to settle which is not supportive of the former diagnosis. Also the urine sample for drug screening proved negative. Her inappropriate giggles and auditory hallucinations suggested a possible diagnosis of schizophrenia. The presence of low serum calcium indicated an organic cause for her abnormal mental health. Depression is a constant feature for some patients with this disorder (Leigh \& Kramer, 1984) and it occurred in all forms of hypo-parathyroidism studies by Denko \& Kaelbling (1962). Feelings of guilt are described only rarely but this patient felt guilty about not being able to look after her children.

Hypocalcaemia may be due to many causes apart from primary hypo-parathyroidism. Routine laboratory screening for 'liver function tests' usually includes a calcium estimation, but as in this instance routine results are not always followed up. Clinicians should be alert to the calcium level in situations associated with hypocalcaemia and where psychiatric disturbance occurs. Also the chance finding of hypocalcaemia must be followed up and related to the clinical status of the patient.

We recommend that although numerous 'routine blood tests' are done in day-to-day psychiatric practice, one must follow any abnormal finding especially when the clinical picture is not typical of the proposed psychiatric diagnosis.

\section{References}

DENKO, J. D. \& KAELBLING, R. (1962) The psychiatric aspects of hypo-parathyroidism. Acta Psychiatrica Scandinavica. 164 (suppl.), 1-70. 
Hifl, P., MURRAY, R. \& THORLEY, A. (1987) Psychiatric manifestations of organic illness. In Essentials of Postgraduate Psychilatry (2nd edn), pp.461-489. London: Grune \& Stratton.

KENDELL. R. \& ZeALLEY, A. K. (1983) Organic disorders. In Companion to Psychiatric Studies (3rd edn), pp. 239-274. Edinburgh: Churchill Ltvingstone.

LEIGH, H. \& KRAMER, S. (1984) The psychiatric manifestations of endocrine disease. Advances in Internal Medictne, 29. 413-445.
LSHMAN, W. A. (1978) Organic Psychiatry. Oxford: Blackwell.

*S. S. Palia, Consultant Psychiatrist, J. Dawkins, SHO Psychiatry and D. Webb, Consultant Physician, Bridgend \& District NHS Trust, Coity Clinic, Princess of Wales Hospital, Bridgend, MidGlam. CF31 1RQ

-Correspondence

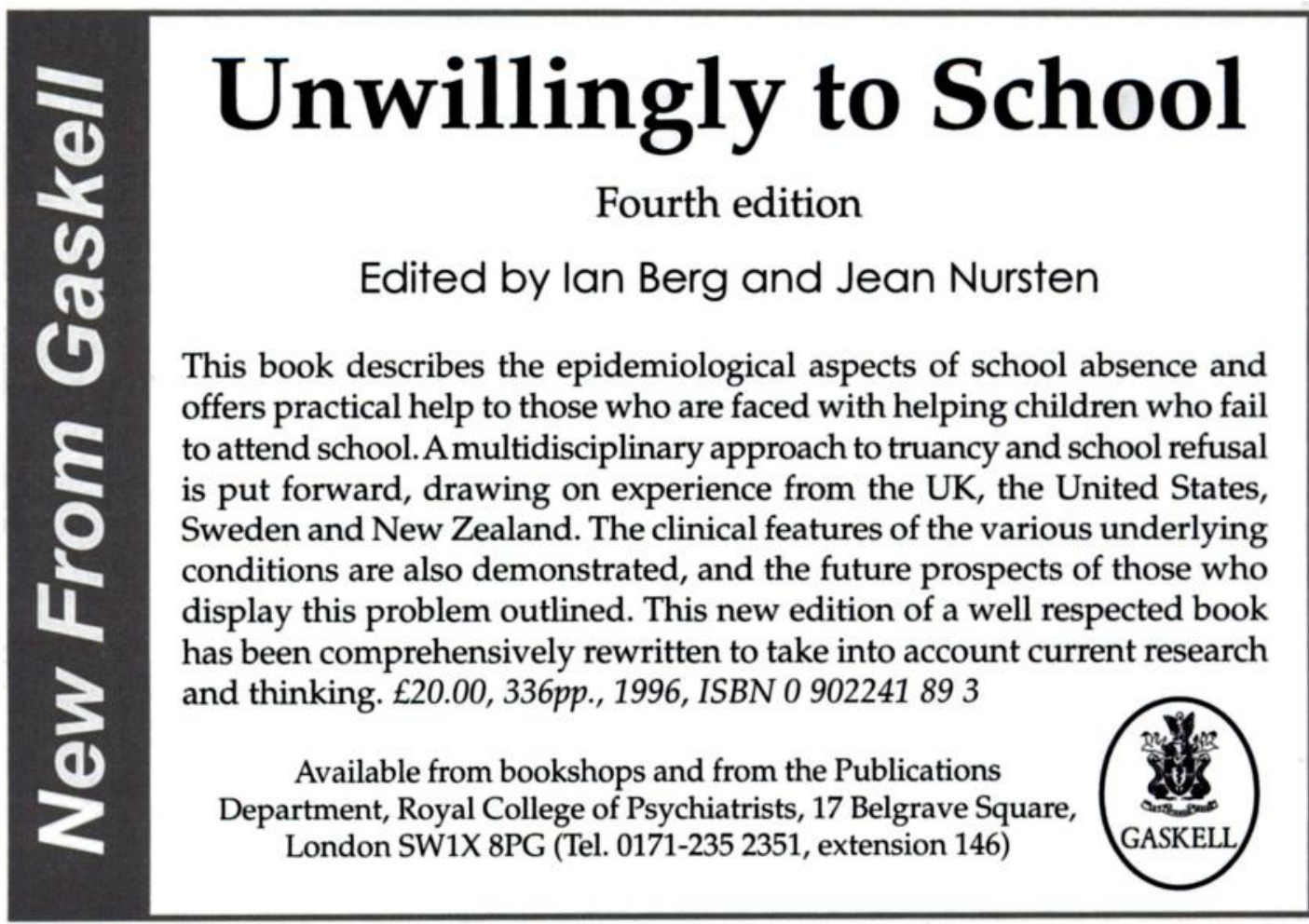

